\title{
SIMPLIFIED CALIBRATION METHODOLOGY OF CHROMATOGRAPHS USED IN CUSTODY TRANSFER MEASUREMENTS OF NATURAL GAS
}

\section{Elcio Cruz de Oliveira}

Petrobras Transporte S.A., Project Management, Av. Presidente Vargas, 328, 20091-060 Rio de Janeiro - RJ, Brazil (هelciooliveira@petrobras.com.br, +55 213211 9223)

\begin{abstract}
The properties, superior calorific value (SCV) and the compressibility factor (z), of 77 natural gas (NG) samples are calculated from two different calibration approaches of gas chromatography, based on ISO 6974-2. The method A uses an analytical curve with seven points that the best adjust is confirmed by Analysis of Variance (ANOVA); it is required when the composition of the natural gas varies. The method B uses a single point calibration, with an allowed tolerance between the calibration gas mixture and sample mole fraction, so it is used to analyze constant natural gas streams. From natural gas composition analyzed by both methods, exceeding the method B allowed tolerance; SCV, $\mathrm{z}$ and its uncertainties are calculated and compared. The results show that all samples that comply with Brazilian legislation can be analyzed by method B, because there are no metrological differences in terms of SCV and z, even though the allowed tolerance has been exceeded. This simplified methodology minimizes operator exposure, besides saving about US\$ 50,000.00 per chromatograph.
\end{abstract}

Keywords: simplified calibration, gas chromatography, superior calorific value, compressibility factor, natural gas.

(C) 2012 Polish Academy of Sciences. All rights reserved

\section{Introduction}

Natural gas (NG) may be considered an excellent and attractive source of fossil energy. For the production, transport, commercialization and consumption of natural gas, it is of paramount economic and technical importance to have an extensive knowledge of its physicochemical properties. Commercial transactions in natural gas are based on its heating value, which depends principally on its chemical composition.

The utilization of on-line chromatographs to analyze the composition of the natural gas has grown exponentially in the energy industry. The Brazilian government, represented by the National Agency for Oil, Natural Gas and Biofuels (ANP) and the National Institute of Metrology, Quality and Technology (INMETRO) has established the specifications for natural gas, to be commercialized throughout Brazilian territory, with a view to guaranteeing accurate and complete results. Within this scenario, the analysis of the natural gas by on-line gas chromatography is the determining parameter for the real-time calculation of the compressibility factor and higher heating value of this fuel.

The Brazilian industry presently utilizes calibration at a single point instead of calibration at multiple points for natural gas chromatography. The reality of the new domestic scenario a combination of different gas streams and the expanding commercialization of liquefied natural gas (LNG) - requires the utilization of an analytical curve, due to these streams not being stable in the Northeast, Central-west, South and Southeast regions of Brazil. However, the on-line chromatographs cannot manage to store the data for a curve with seven certified reference materials (CRMs), in addition to that methodology having a high cost and exposing the operator even more to unhealthy conditions. This cost may be measured at approximately 
US\$ 50,000.00 per chromatograph, and considering that there are 35 chromatographs in Petrobras Transporte S.A. - Transpetro which are subject to this situation, it is estimated at a total of more than US $\$ 1,600,000.00$ per year. The objective of this work is to demonstrate up to which point the difference in the mole fractions calculated by these two approaches has a metrological effect on the superior calorific value (SCV) and the compressibility factor of natural gas. If this is possible, the simplified methodology can substitute the more complex ones or extend the range of calibration work at a single point.

\section{Theoretical Basis}

The result of a measurement is considered the best estimation of the value of measurement accompanied by all the sources of uncertainty that contribute to its propagation $[1,2]$. Consequently, the result of a measurement cannot be interpreted correctly without knowledge about the uncertainty in the result [1].

The evaluation of uncertainty according to GUM (also known as the bottom-up approach) consists of the identification and quantification of the relevant sources of uncertainty [3], followed by the combination of their individual estimates. When expressed as a standard deviation, a component of uncertainty is known as a standard uncertainty, $u(x)$. If there is a correlation between some components, then the correlation or covariance must be calculated.

For a measurement result $x$, the combined standard uncertainty, $u_{c}(x)$ is an estimate of the combined standard deviation, and is equal to the positive square root of the total variance obtained from the combination of all the components of uncertainty evaluated, using the law of propagation of uncertainty (LPU). LPU is based on two facts: the linearization of the equation of measurements (using Taylor Series [2] or the numerical methods) and on the theorem of the variance of the sum of random variables. Suppose that the magnitude of output $\hat{y}=f\left(b_{1}, b_{2}, \ldots, b_{n}\right)$ depends on $n$ magnitudes of input $b_{1}, b_{2}, \ldots, b_{n}$, where each $b_{i}$ is described by an appropriate distribution of probability. The combined standard uncertainty assumes the form of Equation (1), when taking into consideration that the magnitudes are not mutually correlated [4]:

$$
u_{c}^{2}(y)=\sum_{i=1}^{n}\left[\frac{\partial f}{\partial b_{i}}\right]^{2} u^{2}\left(b_{i}\right)
$$

For many applications in Analytical Chemistry [5], the expanded uncertainty is used. Expanded uncertainty $U(x)$ represents the interval within which the value measured is believed to be with a certain confidence level. $U(x)$ is obtained by multiplying $u_{c}(x)$, the combined standard uncertainty, by a coverage factor $k$ :

$$
U(y)=k u_{c}(y)
$$

The choice of the $k$ factor is based on the level of confidence required. The degrees of freedom can be calculated as:

$$
v_{\text {eff }}=\frac{u_{c}^{4}(y)}{\sum_{i=1}^{n}\left(\frac{u_{i}^{4}(y)}{v_{i}}\right)} .
$$




\subsection{Determination of the mole composition and uncertainty of natural gas utilizing a single calibration point: Method B of ISO 6974-2 [6]}

The mathematical model utilized to calculate the non-normalized mole fraction of the component $i$ in natural gas chromatography is:

$$
X_{i}=x_{C R M, i} \frac{R_{i}}{R_{C R M, i}}
$$

where: $X_{i}$ is the non-normalized mole fraction of the component $i ; x_{C R M, i}$ is the mole fraction of component $i$ of the CRM, available on the certificate; $R_{i}$ and $R_{C R M, i}$ represent the area of the corresponding peaks for the analyzed sample and the CRM.

The relative uncertainty in the non-normalized mole fraction of the component $i, X i$, as follows from equation (1) for non-correlated quantities, can be calculated as [7]:

$$
\left(\frac{u\left(X_{i}\right)}{X_{i}}\right)^{2}=\left(\frac{u\left(x_{C R M, i}\right)}{x_{C R M, i}}\right)^{2}+\left(\frac{u\left(R_{C R M, i}\right)}{R_{C R M, i}}\right)^{2}+\left(\frac{u\left(R_{i}\right)}{R_{i}}\right)^{2},
$$

where: $u\left(X_{i}\right)$ is the uncertainty of the non-normalized mole fraction of component $i ; u\left(x_{C R M, i}\right)$ is the uncertainty of the mole fraction of component $i$ of the CRM, available on the certificate; $u\left(R_{C R M, i}\right)$ is the uncertainty of the area of the peak of the component $i$ of the CRM analyzed; $u\left(R_{i}\right)$ is the uncertainty of the area of the peak of the component $i$ in the sample analyzed.

However, when the limits given in Table 1 are exceeded, it becomes necessary to construct an analytical curve with seven calibration points, item 2.2.

Table 1. Maximum allowable tolerances between the NG sample and the CRM [6].

\begin{tabular}{|cc|}
\hline $\begin{array}{c}\text { Sample - Mole fraction of the } \\
\text { component, } \%\end{array}$ & $\begin{array}{c}\text { Deviation \% between the mole fraction of the component of } \\
\text { the sample and the CRM }\end{array}$ \\
\hline 0.001 to 0.1 & \pm 100 \\
0.1 to 1 & \pm 50 \\
1 to 10 & \pm 10 \\
10 to 50 & \pm 5 \\
50 to 100 & \pm 3 \\
\hline
\end{tabular}

\subsection{Determination of the mole composition and uncertainty of natural gas utilizing a (multipoint) analytical curve: Method A of ISO 6974-2}

In an unweighted regression with homoscedastic characteristics (Cochran test), first one removes the outliers with the use of the Grubbs test. Starting with $n$ data points on the calibration curve with linear adjustments, $\left(y=b_{0}+b_{1} c\right)$, and for $p$ number of measurements to determine $y_{0}$, the combined uncertainty in $c_{0}$ is generally calculated from Equation (6) $[5,8]$ :

$$
u_{c}(c)=\frac{S}{b_{1}} \times \sqrt{\frac{1}{p}+\frac{1}{n}+\frac{(c-\bar{c})^{2}}{\sum_{j=1}^{n}\left(c_{j}-\bar{c}\right)^{2}}},
$$


where:

$$
S=\sqrt{\frac{\sum_{j=1}^{n}\left[A_{j}-\left(b_{0}+b_{1} \times c_{j}\right)\right]^{2}}{n-2}},
$$

$b_{1}$ and $b_{0}-$ slope and intercept of the calibration curve; $p$ - number of measurements to determine $c ; n$ - number of measurements for the analytic curve; $c$ - concentration of the component; $\bar{c}-$ average value of the different calibration standards ( $n$ number of measurements); $A_{j}-$ the $j^{\text {th }}$ landmark measurement from the $i^{\text {th }}$ calibration standard; $j$ - index of the number of measurements to obtain the analytical curve.

Verification of the linearity must be evaluated visually by analyzing the regression residues, and numerically by analyzing the variances (Anova), although some authors still use the proximity of the determination coefficient to the unit [9]. The total variability of the responses is derived from the sum of the squares due to the regression and the sum of the squares of the residuals; the latter is decomposed into lack of fit and pure error sums of the square.

The Anova table may be constructed from the equations in Table 2.

One significant ratio $M S_{R E G} / M S_{R}$ confirms that there is regression. If the ratio $M S_{L O F} / M S_{P E}$ is higher than the critical value, the linear model is inadequate. The nonsignificant lack of fit indicates there appears to be no reason to doubt the adequacy of the model and both the pure error and the lack of fit to the average of the squares may be used as estimates of the variance $\sigma^{2}$.

Table 2. Anova for an unweighted regression.

\begin{tabular}{|lcccc|}
\hline Source of variation & Sum of squares, $S S$ & $\begin{array}{c}\text { Degree of } \\
\text { freedom, } d f\end{array}$ & $\begin{array}{c}\text { Mean squares, } \\
M S=S S / d f\end{array}$ & $F$ \\
Regression, $R E G$ & $S S_{R E G}$ & 1 & $M S_{R E G}$ & $M S_{R E G} / M S_{R}$ \\
Residual, $R$ & $S S_{R}$ & $n-2$ & $M S_{R}$ & \\
Lack of fit, $L O F$ & $S S_{L O F}$ & $k-2$ & $M S_{L O F}$ & $M S_{L O F} / M S_{P E}$ \\
$\quad$ Pure error, $P E$ & $S S_{P E}$ & $n-k$ & $M S_{P E}$ & \\
Total & $S S_{T}$ & $n-1$ & & \\
\hline
\end{tabular}

Symbols in the Table denote:

$k$ - number of levels; $n$ - total number of observations.

$$
\begin{aligned}
& S S_{R}=\sum_{i}^{k} \sum_{j}^{n_{i}}\left(y_{i j}-\bar{y}_{i}\right)^{2}+\sum_{i}^{k} n_{i}\left(\bar{y}_{i}-\hat{y}_{i}\right)^{2} ; \quad S S_{R E G}=\sum_{i}^{k} n_{i}\left(\hat{y}_{i}-\bar{y}\right)^{2} ; \quad S S_{T}=S S_{R}+S S_{R E G} ; \\
& S S_{P E}=\sum_{i}^{k} \sum_{j}^{n_{i}}\left(y_{i j}-\bar{y}_{i}\right)^{2} ; S S_{L O F}=\sum_{i}^{k} n_{i}\left(\bar{y}_{i}-\hat{y}_{i}\right)^{2} ; M S_{R E G}=S S_{R E G} /(k-1) ; M S_{R}=S S_{R} /(n-k) .
\end{aligned}
$$

Equations (5) and (6) in items 2.1 and 2.2 calculate the combined uncertainty of the nonnormalized mole fraction, through the calibration at a single point and at multiple points respectively.

The mathematical model applied to calculate the normalized mole fraction of component $i$ in the sample, $x_{i}$, is:

$$
x_{i}=\frac{X_{i}}{\sum_{w=1}^{q} X_{w}},
$$


where: $x_{i}$ is the normalized mole fraction of component $i$ and $X_{w}$ is the corresponding nonnormalized one.

The uncertainty in the normalized mole fraction of component $i$ from sample, is:

$$
u_{c}\left(x_{i}\right)=x_{i} \sqrt{\frac{1-2 X_{i}}{X_{i}^{2}} u\left(X_{i}\right)^{2}+\sum_{w=1}^{q} u\left(X_{w}\right)^{2}} .
$$

\subsection{Uncertainty of the compressibility factor and the superior calorific value of natural gas [10]}

In this work, the calorific value and the specific mass of ideal gas in the basic conditions $(101.325 \mathrm{kPa}$ and $293.15 \mathrm{~K})$ are calculated from the mole composition and the respective ideal values for the components based on the standard ISO 6976 - 95 [11]. These values are then adjusted by a factor of compressibility.

The measurement uncertainty is calculated from the expansion of the Taylor Series, considering the non-correlated quantities among themselves and a coverage factor that is equal to 2 for a $95.45 \%$ confidence level.

\subsubsection{Compressibility factor}

The compressibility factor ${ }^{1}$ is calculated as:

$$
Z_{(t, p)}=1-\left[\sum_{j=1}^{n} x_{j} \sqrt{\beta_{j j}}\right]^{2},
$$

where: $Z_{(t, p)}$ - compressibility factor of gas at base temperature and pressure conditions; $x_{j}-$ mole fraction of component $j ; n$ - total number of components; $\sqrt{\beta_{j j}}$ - additional factor of component $j$ (values contained in Chart 1).

Chart 1 shows an example of calculating properties of natural gas, using a typical Brazilian natural gas and constants based on reference [11].

Chart 1. Example of calculating properties of natural gas at normal conditions.

\begin{tabular}{|c|c|c|c|c|c|c|c|}
\hline Components & $x_{j}$ & $\sqrt{\beta_{j j}}$ & $x_{j} \sqrt{\beta_{j j}}$ & $\frac{M_{j}}{M_{\text {air }}}$ & $x_{j} \frac{M_{j}}{M_{\text {air }}}$ & $\begin{array}{c}I S C V \\
{\left[\mathrm{~kJ} / \mathrm{m}^{3}\right]}\end{array}$ & $\begin{array}{c}x_{j} I S C V \\
{\left[\mathrm{~kJ} / \mathrm{m}^{3}\right]}\end{array}$ \\
\hline Methane & 0.9208 & 0.0436 & 0.04015 & 0.55392 & 0.51006 & 37044 & 34111 \\
\hline Ethane & 0.05359 & 0.0894 & 0.00479 & 1.03824 & 0.05564 & 64910 & 3479 \\
\hline Propane & 0.01451 & 0.1288 & 0.00187 & 1.52255 & 0.02209 & 92290 & 1339 \\
\hline Isobutane & 0.00061 & 0.1703 & 0.00010 & 2.00683 & 0.00122 & 119280 & 73 \\
\hline Butane & 0.00085 & 0.1783 & 0.00015 & 2.00683 & 0.00171 & 119660 & 102 \\
\hline Isopentane & 0.00006 & 0.2168 & 0.00001 & 2.49114 & 0.00015 & 146760 & 9 \\
\hline Pentane & 0.00006 & 0.2345 & 0.00001 & 2.49114 & 0.00015 & 147040 & 9 \\
\hline Neopentane & negligible & 0.2025 & 0.00236 & 2.49114 & 0.00000 & 146160 & 0 \\
\hline Hexane & 0.00007 & 0.2846 & 0.00002 & 2.97546 & 0.00021 & 174460 & 12 \\
\hline Nitrogen & 0.00590 & 0.0173 & 0.00010 & 0.96723 & 0.00571 & 0 & 0 \\
\hline CO 2 & 0.00353 & 0.0728 & 0.00026 & 1.51955 & 0.00536 & 0 & 0 \\
\hline Oxygen & negligible & 0.0000 & & 1.10483 & 0.00000 & 0 & 0 \\
\hline$\sum_{j=1}^{n}$ & $\mathbf{1 . 0 0 0 0 0}$ & - & $\mathbf{0 . 0 4 7 4 6}$ & - & $\mathbf{0 . 6 0 2 3 0}$ & - & $\mathbf{3 9 1 3 3}$ \\
\hline
\end{tabular}

\footnotetext{
${ }^{1}$ Relationship between the real volume of a given mass of gas and the calculated volume of this mass based on the law of ideal gases, at the same temperature and pressure conditions.
} 
Uncertainty in the compressibility factor is given by Equations 11 and 12, and based on reference [11], the uncertainty of $\sqrt{\beta_{j j}}$ is $0.1 \%$ :

$$
\begin{gathered}
u_{c}^{2}(Z)=\left(\frac{\partial z}{\partial x_{j}} u\left(x_{j}\right)\right)^{2}+\left(\frac{\partial z}{\partial \beta_{j j}} u\left(\beta_{j j}\right)\right)^{2}, \\
u_{c}^{2}(Z)=\sum_{i=1}^{n}\left(-2 \sqrt{\beta_{i i}} \sum_{j=1}^{n} x_{j} \sqrt{\beta_{j j}}\right)^{2} u^{2}\left(x_{j}\right)+\sum_{i=1}^{n}\left(-2 x_{j} \sum_{j=1}^{n} x_{j} \sqrt{\beta_{j j}}\right)^{2} u^{2}\left(\sqrt{\beta_{j j}}\right), \\
u_{c}^{2}(Z)=4(1-Z) \sum_{i=1}^{n}\left[\left(\sqrt{\beta_{j j}}\right)^{2} u^{2}\left(x_{j}\right)+x_{j}^{2} u^{2}\left(\sqrt{\beta_{j j}}\right)\right] .
\end{gathered}
$$

\subsubsection{Ideal relative density (IDR) of the gas}

The ideal relative density of the gas is calculated using Equation 14:

$$
I D R=\sum_{j=1}^{n} x_{j} \frac{M_{j}}{M_{a r}}
$$

where: IDR - ideal relative density of the gas; $n$ - total number of the components; $x_{j}-$ mole fraction of the component $j ; M_{j} / M_{\text {air }}$ - ratio between the molecular mass of component $j$ and the molecular mass of air (Chart 1).

Uncertainty in the ideal relative density of the gas is given using Equations 15 and 16,

$$
\begin{gathered}
u_{c}^{2}(I D R)=\left(\frac{\partial I D R}{\partial x_{j}} u\left(x_{j}\right)\right)^{2}+\left(\frac{\partial I D R}{\partial M_{j}} u\left(M_{j}\right)\right)^{2}+\left(\frac{\partial I D R}{\partial M_{\text {air }}} u\left(M_{\text {air }}\right)\right)^{2}, \\
u_{c}^{2}(I D R)=\sum_{i=1}^{n}\left(\left(\frac{M_{j}}{M_{\text {air }}}\right)^{2} u^{2}\left(x_{j}\right)+\left(\frac{x_{j}}{M_{\text {air }}}\right)^{2} u^{2}\left(M_{j}\right)+\left(\frac{-x_{j} M_{j}}{M_{\text {air }}^{2}}\right)^{2} u^{2}\left(M_{\text {air }}\right)\right) .
\end{gathered}
$$

Based on reference [11], the uncertainty of $M_{\text {air }}$ is $0.1 \%$.

\subsubsection{Real relative density (RRD) of the gas}

The real relative density of the gas under the basic conditions of temperature and pressure is given using Equation 17:

$$
R R D=I D R \frac{Z_{\text {air }}}{Z}
$$

where: $Z_{a i r}-$ compressibility factor of dry air in basic condition $\left(Z_{a i r}=0.99963\right) ; Z-$ compressibility factor of the gas.

Uncertainty in the real relative density of the gas is given by Equations 18 and 19:

$$
u_{c}^{2}(R R D)=\left(\frac{\partial R R D}{\partial I D R} u(I D R)\right)^{2}+\left(\frac{\partial R R D}{\partial Z_{\text {air }}} u\left(Z_{\text {air }}\right)\right)^{2}+\left(\frac{\partial R R D}{\partial Z} u(Z)\right)^{2},
$$




$$
u_{c}^{2}(R R D)=\left(\frac{Z_{\text {air }}}{Z} u(I D R)\right)^{2}+\left(\frac{I D R}{Z} u\left(Z_{\text {air }}\right)\right)^{2}+\left(-\frac{I D R \times Z_{\text {air }}}{Z^{2}} u(Z)\right)^{2}
$$

\subsubsection{Ideal superior calorific value (ISCV) per unit of volume}

The superior calorific value per unit of volume is calculated using Equation 20:

$$
I S C V=\sum_{j=1}^{n} x_{j} I S C V_{j},
$$

where: $x_{j}$ - mole fraction of the component $j ; n$ - total number of components; $I S C V_{j}-$ ideal superior calorific value per unit of volume of the component (Chart 1).

The uncertainty in the ideal superior calorific value per unit of the gas is given using Equations 21 and 22:

$$
\begin{aligned}
& u_{c}^{2}(I S C V)=\left(\frac{\partial I S C V}{\partial x_{j}} u\left(x_{j}\right)\right)^{2}+\left(\frac{\partial I S C V}{\partial I S C V_{j}} u\left(I S C V_{j}\right)\right)^{2} \\
& u_{c}^{2}(I S C V)=\sum_{i=1}^{n}\left(\left(I S C V_{j}\right)^{2} u^{2}\left(x_{j}\right)+\left(x_{j}\right)^{2} u^{2}\left(I S C V_{j}\right)\right) .
\end{aligned}
$$

\subsubsection{Real superior calorific value per unit of volume}

The real superior calorific value per unit of volume is calculated using Equation 23:

$$
R S C V=\frac{I S C V}{Z}
$$

where: $R S C V$ - real superior calorific value of the gas per unit of volume; ISCV - ideal superior calorific value of the gas per unit of volume.

Uncertainty in the real superior calorific value of the gas by unit of volume is given using Equations 24 and 25:

$$
\begin{aligned}
& u_{c}^{2}(R S C V)=\left(\frac{\partial R S C V}{\partial I S C V} u(I S C V)\right)^{2}+\left(\frac{\partial R S C V}{\partial Z} u(Z)\right)^{2}, \\
& u_{c}^{2}(R S C V)=\left(\frac{1}{Z} \times u(I S C V)\right)^{2}+\left(-\frac{I S C V}{Z^{2}} \times u(Z)\right)^{2}
\end{aligned}
$$

\subsection{Test of the hypotheses}

Two systems of measurement are considered without significant difference, if the absolute value of the difference between the measurements is less or equal to the square root of the sum of the squares of the expanded uncertainties:

$$
\left|R_{1}-R_{2}\right| \leq \sqrt{U_{1}^{2}+U_{2}^{2}}
$$

where $R_{1} \pm U_{1}$ is the result of the first measurement system and $R_{2} \pm U_{2}$ is the result of the second measurement system. 


\subsection{Specification of natural gas}

Resolution No. 16, dated 17 June 2008, establishes the specification for natural gas of either domestic or foreign origin to be commercialized throughout Brazilian territory, Chart 2.

Chart 2. Specification of natural gas [12].

\begin{tabular}{|c|c|c|c|c|c|c|c|}
\hline \multirow[b]{2}{*}{ Characteristic } & \multirow[b]{2}{*}{ Unity } & \multicolumn{3}{|c|}{ Limit (Brazilian Region) } & \multicolumn{3}{|c|}{ Method } \\
\hline & & North & Northeast & $\begin{array}{c}\text { Central-west, } \\
\text { South and } \\
\text { Southeast }\end{array}$ & $\begin{array}{l}\text { Brazilian } \\
\text { Standard }\end{array}$ & ASTM D & ISO \\
\hline SCV & $\mathrm{kJ} / \mathrm{m}^{3}$ & 34,000 to 38,400 & \multicolumn{2}{|c|}{35,000 to 43,000} & 15213 & 3588 & 6976 \\
\hline Methane, min & mole $\%$ & 68.0 & \multicolumn{2}{|r|}{85.0} & 14903 & 1945 & 6974 \\
\hline
\end{tabular}

\section{Experimental}

18 (eighteen) certified reference materials were selected for this study (Annex 1). Of these eighteen, seven were utilized for the construction of an analytical curve, and another seven for the calibration at a single point; resulting in a total of 77 (seventy seven) samples to be compared by the two methodologies. The data were processed to evaluate whether the compressibility factor and the superior calorific value of the natural gas, calculated from the mole fractions with a single point calibration presented the same values metrologically as when calculated with multipoint calibration.

The tests were carried out in a Daniel Danalyzer ${ }^{\mathrm{TM}}$ Model 500 Gas Chromatograph, in the Campos Elíseos Terminal in May 2011.

\section{Results and discussion}

\subsection{Linear adjustment to the multipoint analytical curve}

All of the components had a linear adjustment in the construction of the analytical curve, when tested by ANOVA; i.e. the values for $M S_{R E G} / M S_{R}$ were higher than $F_{\text {critical }}$ and the values for $M S_{L O F} / M S_{P E}$ were less than $F_{\text {critical }}$, Chart 3.

Fig. 1 confirms visually the ANOVA approach, through the random distribution of residues from the linear regression for the methane, as discussed in item 2.2.

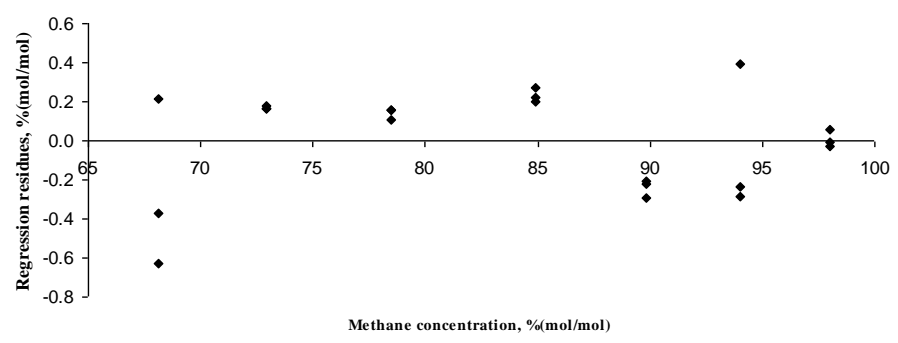

Fig. 1. Residue analysis.

\subsection{Superior calorific value}

The results in italics and underlined, in Annex 2, are those in which the hypothesis tests, item 2.4, show significant differences between the two methodologies: multipoint calibration (analytical curve) - Method A and single point calibration - Method B. Some of these results are shown in Fig. 2. In these situations, there are no overlaps between confidence intervals of methods $\mathrm{A}$ and $\mathrm{B}$, in terms of superior calorific value of the natural gas. 
Chart 3. Results of the adjustments to the analytical curves (concentration versus peak areas).

\begin{tabular}{|c|c|c|c|c|c|c|c|}
\hline \multicolumn{4}{|c|}{ METHANE } & \multicolumn{4}{|c|}{ ETHANE } \\
\hline 68.10 & $3.8021 \mathrm{E}+08$ & $3.8321 \mathrm{E}+08$ & $3.8453 \mathrm{E}+08$ & 11.00 & $9.9549 \mathrm{E}+07$ & $9.9439 \mathrm{E}+07$ & $9.9480 \mathrm{E}+07$ \\
\hline 72.90 & $4.0496 \mathrm{E}+08$ & $4.0495 \mathrm{E}+08$ & $4.0489 \mathrm{E}+08$ & 8.500 & 7.6707E+07 & $7.6552 \mathrm{E}+07$ & 7.6791E+07 \\
\hline 78.50 & $4.3356 \mathrm{E}+08$ & $4.3380 \mathrm{E}+08$ & $4.3358 \mathrm{E}+08$ & 7.000 & $6.3351 \mathrm{E}+07$ & $6.3442 \mathrm{E}+07$ & $6.3328 \mathrm{E}+07$ \\
\hline 84.90 & $4.6564 \mathrm{E}+08$ & $4.6589 \mathrm{E}+08$ & $4.6601 \mathrm{E}+08$ & 5.290 & $4.7781 \mathrm{E}+07$ & $4.8189 \mathrm{E}+07$ & $4.8015 \mathrm{E}+07$ \\
\hline 89.82 & $4.9318 \mathrm{E}+08$ & $4.9324 \mathrm{E}+08$ & $4.9362 \mathrm{E}+08$ & 4.338 & $3.9177 \mathrm{E}+07$ & $3.9108 \mathrm{E}+07$ & $3.9631 \mathrm{E}+07$ \\
\hline 94.00 & $5.1463 \mathrm{E}+08$ & $5.1489 \mathrm{E}+08$ & $5.1141 \mathrm{E}+08$ & 3.230 & $2.9434 \mathrm{E}+07$ & $2.9266 \mathrm{E}+07$ & $2.9428 \mathrm{E}+07$ \\
\hline 98.00 & $5.3356 \mathrm{E}+08$ & $5.3386 \mathrm{E}+08$ & $5.3399 \mathrm{E}+08$ & 0.881 & $8.3303 \mathrm{E}+06$ & $8.3972 \mathrm{E}+06$ & $8.2834 \mathrm{E}+06$ \\
\hline$M S_{R E G} / M S_{R}$ & $30684>$ & $\mathrm{F}_{\text {CRITICAL }}$ & 4.38 & $M S_{R E G} / M S_{R}$ & $643132>$ & $\mathrm{F}_{\text {CRITICAL }}$ & 4.38 \\
\hline$M S_{L O F} / M S_{P E}$ & $2.86<$ & $\mathrm{F}_{\text {CRITICAL }}$ & 2.96 & $M S_{L O F} / M S_{P E}$ & $1.63<$ & $\mathrm{F}_{\text {CRITICAL }}$ & 2.96 \\
\hline \multicolumn{4}{|c|}{ PROPANE } & \multicolumn{4}{|c|}{ BUTANE } \\
\hline 2.89 & $3.1858 \mathrm{E}+07$ & $3.1877 \mathrm{E}+07$ & $3.1880 \mathrm{E}+07$ & 0.2010 & $2.6101 \mathrm{E}+06$ & $2.5657 \mathrm{E}+06$ & $2.5828 \mathrm{E}+06$ \\
\hline 4.00 & $4.3888 \mathrm{E}+07$ & $4.3895 \mathrm{E}+07$ & $4.3914 \mathrm{E}+07$ & 0.1000 & $1.2170 \mathrm{E}+06$ & $1.1940 \mathrm{E}+06$ & $1.1665 \mathrm{E}+06$ \\
\hline 3.44 & $3.7803 \mathrm{E}+07$ & $3.7807 \mathrm{E}+07$ & $3.7747 \mathrm{E}+07$ & 0.3990 & $5.1820 \mathrm{E}+06$ & $5.1093 \mathrm{E}+06$ & $5.2341 \mathrm{E}+06$ \\
\hline 1.80 & $1.9856 \mathrm{E}+07$ & $2.0021 \mathrm{E}+07$ & $1.9910 \mathrm{E}+07$ & 0.5450 & $7.0119 \mathrm{E}+06$ & $6.7866 \mathrm{E}+06$ & $6.8992 \mathrm{E}+06$ \\
\hline 1.49 & $1.6454 \mathrm{E}+07$ & $1.6550 \mathrm{E}+07$ & $1.6516 \mathrm{E}+07$ & 0.1980 & $2.6003 \mathrm{E}+06$ & $2.4706 \mathrm{E}+06$ & $2.4877 \mathrm{E}+06$ \\
\hline 1.08 & $1.1949 \mathrm{E}+07$ & $1.2082 \mathrm{E}+07$ & $1.1885 \mathrm{E}+07$ & 0.1100 & $1.4039 \mathrm{E}+06$ & $1.2858 \mathrm{E}+06$ & $1.3433 \mathrm{E}+06$ \\
\hline 0.0709 & $7.0540 \mathrm{E}+05$ & $9.7514 \mathrm{E}+05$ & $8.0211 \mathrm{E}+05$ & 0.0101 & $1.5870 \mathrm{E}+05$ & $7.8288 \mathrm{E}+04$ & $1.1937 \mathrm{E}+05$ \\
\hline$M S_{R E G} / M S_{R}$ & $515075>$ & $\mathrm{F}_{\text {CRITICAL }}$ & 4.38 & $M S_{R E G} / M S_{R}$ & $17784>$ & $\mathrm{F}_{\text {CRITICAL }}$ & 4.38 \\
\hline$M S_{L O F} / M S_{P E}$ & $2.66<$ & $\mathrm{F}_{\text {CRITICAL }}$ & 2.96 & $M S_{L O F} / M S_{P E}$ & $2.75<$ & $\mathrm{F}_{\text {CRITICAL }}$ & 2.96 \\
\hline \multicolumn{4}{|c|}{ ISOPENTANE } & \multicolumn{4}{|c|}{ HEXANE } \\
\hline 0.2000 & $2.9400 \mathrm{E}+06$ & $2.9544 \mathrm{E}+06$ & $2.9645 \mathrm{E}+06$ & 20 & $3.6398 \mathrm{E}+06$ & $3.5783 \mathrm{E}+06$ & $3.5258 \mathrm{E}+06$ \\
\hline 0.1500 & $2.2528 \mathrm{E}+06$ & $2.2328 \mathrm{E}+06$ & $2.2139 \mathrm{E}+06$ & 0.1000 & $1.7901 \mathrm{E}+06$ & $1.7437 \mathrm{E}+06$ & $1.8599 \mathrm{E}+06$ \\
\hline 0.2980 & $4.4594 \mathrm{E}+06$ & $4.4244 \mathrm{E}+06$ & $4.4058 \mathrm{E}+06$ & 0.2490 & $4.2780 \mathrm{E}+06$ & $4.3808 \mathrm{E}+06$ & $4.2925 \mathrm{E}+06$ \\
\hline 0.2450 & $3.6016 \mathrm{E}+06$ & $3.6115 \mathrm{E}+06$ & $3.6397 \mathrm{E}+06$ & 0.0500 & $9.0110 \mathrm{E}+05$ & $8.9996 \mathrm{E}+05$ & $9.0054 \mathrm{E}+05$ \\
\hline 0.0367 & $5.2070 \mathrm{E}+05$ & $5.2510 \mathrm{E}+05$ & $5.2566 \mathrm{E}+05$ & 0.0192 & $3.4330 \mathrm{E}+05$ & $3.4388 \mathrm{E}+05$ & $3.4354 \mathrm{E}+05$ \\
\hline 0.0300 & $4.2186 \mathrm{E}+05$ & $4.2161 \mathrm{E}+05$ & $4.1653 \mathrm{E}+05$ & 0.0399 & $6.7415 \mathrm{E}+05$ & $6.7356 \mathrm{E}+05$ & $6.7243 \mathrm{E}+05$ \\
\hline 0.0103 & $1.4450 \mathrm{E}+05$ & $1.4606 \mathrm{E}+05$ & $1.4298 \mathrm{E}+05$ & 0.0100 & $1.7394 \mathrm{E}+05$ & $1.7365 \mathrm{E}+05$ & $1.7416 \mathrm{E}+05$ \\
\hline$M S_{R E G} / M S_{R}$ & $173595>$ & $\overline{F_{\text {CRITICAL }}}$ & 4.38 & $M S_{R E G} / M S_{R}$ & $23133>$ & $\overline{F_{\text {CRITICAL }}}$ & 4.38 \\
\hline$M S_{L O F} / M S_{P E}$ & $2.02<$ & $\mathrm{F}_{\text {CRITICAL }}$ & 2.96 & $M S_{L O F} / M S_{P E}$ & $2.94<$ & $\mathrm{F}_{\text {CRITICAL }}$ & 2.96 \\
\hline \multicolumn{4}{|c|}{ CARBON DIOXIDE } & \multicolumn{4}{|c|}{ ISOBUTANE } \\
\hline 2.890 & $2.3306 \mathrm{E}+07$ & $2.3645 \mathrm{E}+07$ & $2.3994 \mathrm{E}+07$ & 0.4020 & $5.0478 \mathrm{E}+06$ & $5.0010 \mathrm{E}+06$ & $5.0948 \mathrm{E}+06$ \\
\hline 2.400 & $1.9986 \mathrm{E}+07$ & $1.9279 \mathrm{E}+07$ & $1.9640 \mathrm{E}+07$ & 0.5010 & $6.1137 \mathrm{E}+06$ & $6.2542 \mathrm{E}+06$ & $6.3989 \mathrm{E}+06$ \\
\hline 1.700 & $1.4406 \mathrm{E}+07$ & $1.4015 \mathrm{E}+07$ & $1.3616 \mathrm{E}+07$ & 0.1000 & $1.3219 \mathrm{E}+06$ & $1.2599 \mathrm{E}+06$ & $1.1984 \mathrm{E}+06$ \\
\hline 0.148 & $1.2506 \mathrm{E}+06$ & $1.2426 \mathrm{E}+06$ & $1.2420 \mathrm{E}+06$ & 0.2970 & $3.7559 \mathrm{E}+06$ & $3.6117 \mathrm{E}+06$ & $3.6837 \mathrm{E}+06$ \\
\hline 1.446 & $1.2307 \mathrm{E}+07$ & $1.1634 \mathrm{E}+07$ & $1.1961 \mathrm{E}+07$ & 0.1970 & $2.4113 \mathrm{E}+06$ & $2.4718 \mathrm{E}+06$ & $2.3603 \mathrm{E}+06$ \\
\hline 0.737 & $5.4644 \mathrm{E}+06$ & $5.4598 \mathrm{E}+06$ & $5.4549 \mathrm{E}+06$ & 0.1100 & $1.6949 \mathrm{E}+06$ & $1.5258 \mathrm{E}+06$ & $1.4128 \mathrm{E}+06$ \\
\hline 0.506 & $4.1583 \mathrm{E}+06$ & $4.1600 \mathrm{E}+06$ & $4.1587 \mathrm{E}+06$ & 0.0101 & $1.1215 \mathrm{E}+05$ & $1.1357 \mathrm{E}+05$ & $1.1197 \mathrm{E}+05$ \\
\hline$M S_{R E G} / M S_{R}$ & $11855>$ & $\overline{F_{\text {CRITICAL }}}$ & 4.38 & $M S_{R E G} / M S_{R}$ & $8328>$ & $\overline{F_{\text {CRITICAL }}}$ & 4.38 \\
\hline$M S_{L O F} / M S_{P E}$ & $2.65<$ & $\mathrm{F}_{\text {CRITICAL }}$ & 2.96 & $M S_{L O F} / M S_{P E}$ & $2.27<$ & $\mathrm{F}_{\text {CRITICAL }}$ & 2.96 \\
\hline \multicolumn{4}{|c|}{ ISOPENTANE } & \multicolumn{4}{|c|}{ NITROGEN } \\
\hline 0.201 & $2.8393 \mathrm{E}+06$ & $2.8143 \mathrm{E}+06$ & $2.8293 \mathrm{E}+06$ & 13.960 & $9.1535 \mathrm{E}+07$ & $9.5174 \mathrm{E}+07$ & $9.3367 \mathrm{E}+07$ \\
\hline 0.100 & $1.4207 \mathrm{E}+06$ & $1.4308 \mathrm{E}+06$ & $1.4443 \mathrm{E}+06$ & 11.240 & 7.6672E+07 & $7.3666 \mathrm{E}+07$ & $7.5189 \mathrm{E}+07$ \\
\hline 0.299 & $4.2338 \mathrm{E}+06$ & $4.2445 \mathrm{E}+06$ & $4.2222 \mathrm{E}+06$ & 7.970 & $5.5280 \mathrm{E}+07$ & $5.3778 \mathrm{E}+07$ & $5.2255 \mathrm{E}+07$ \\
\hline 0.020 & $2.9241 \mathrm{E}+05$ & $2.7971 \mathrm{E}+05$ & $2.6850 \mathrm{E}+05$ & 6.760 & $4.4164 \mathrm{E}+07$ & $4.5592 \mathrm{E}+07$ & $4.7010 \mathrm{E}+07$ \\
\hline 0.034 & $4.7236 \mathrm{E}+05$ & $4.6126 \mathrm{E}+05$ & $4.8388 \mathrm{E}+05$ & 2.418 & $1.7868 \mathrm{E}+07$ & $1.4674 \mathrm{E}+07$ & $1.6468 \mathrm{E}+07$ \\
\hline 0.050 & $7.1459 \mathrm{E}+05$ & $7.0289 \mathrm{E}+05$ & $6.9022 \mathrm{E}+05$ & 0.599 & $7.5707 \mathrm{E}+06$ & $8.2245 \mathrm{E}+06$ & $7.8049 \mathrm{E}+06$ \\
\hline 0.010 & $1.3870 \mathrm{E}+05$ & $1.4969 \mathrm{E}+05$ & $1.2707 \mathrm{E}+05$ & 0.505 & $3.0753 \mathrm{E}+06$ & $3.5795 \mathrm{E}+06$ & $4.0746 \mathrm{E}+06$ \\
\hline$M S_{R E G} / M S_{R}$ & $216192>$ & $\mathrm{F}_{\text {CRITICAL }}$ & 4.38 & $M S_{R E G} / M S_{R}$ & $7934>$ & $\mathrm{F}_{\text {CRITICAL }}$ & 4.38 \\
\hline$M S_{L O F} / M S_{P E}$ & $2.61<$ & $\mathrm{F}_{\text {CRITICAL }}$ & 2.96 & $M S_{L O F} / M S_{P E}$ & $2.84<$ & $\mathrm{F}_{\text {CRITICAL }}$ & 2.96 \\
\hline
\end{tabular}

The rectangle outlined in black in Annex 2 shows the range of confidence in which the results of the two methodologies are in agreement. The normalized composition values that do not reach $98 \%$ were discarded from this comparison.

For a better understanding of these results, there follows the detail of a case of comparison between the two methodologies, for each range of variation in Table 1. 


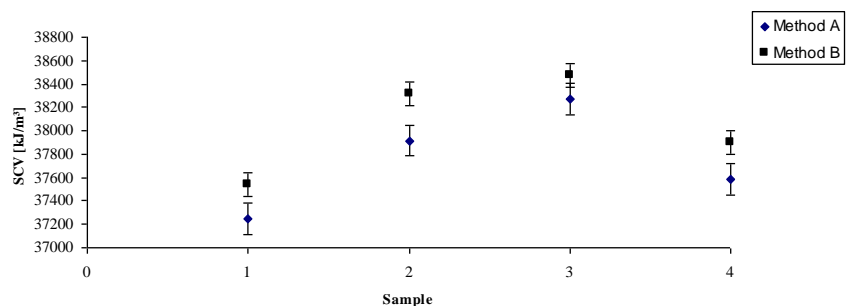

Fig. 2. Test of the hypotheses between methods A and B.

\subsubsection{Mole fraction of the component between $0.001 \%$ and $0.1 \%$ : difference of $\pm 100 \%$}

If the calibration of the chromatograph is considered at standard 5 (sample 14) which contains $0.040 \%$ of hexane; from Table 1 , the maximum values of this component to be analyzed must be between $0.000 \%$ and $0.080 \%$. Sample 13 contains $0.150 \%$ of hexane, which is outside the maximum allowable limits; however, metrological differences were not observed in the higher heating value or the compressibility factor of the natural gas, when calculated by methods A and B of ISO 6974-2.

\subsubsection{Mole fraction of the component between $0.1 \%$ and $1 \%$ : difference of $\pm 50 \%$}

If the calibration of the chromatograph is considered at standard 1 (sample 2) which contains $0.280 \%$ of isobutane; from Table 1 , the maximum values of this component to be analyzed must be between $0.140 \%$ and $0.420 \%$. Sample 7 presented $0.601 \%$ of isobutane, which is outside the maximum allowable limits; however, metrological differences were not observed in the higher heating value or the compressibility factor, when calculated by methods A and B of ISO 6974-2.

\subsubsection{Mole fraction of the component between $1 \%$ and $10 \%$ : difference of $\pm 10 \%$}

If the calibration of the chromatograph is considered at standard 4 (sample 11) which contains $2.220 \%$ of propane; from Table 1, the maximum values of this component to be analyzed must be between $1.980 \%$ and $2.420 \%$. Sample 7 presented $0.703 \%$ of propane, which is outside the maximum allowable limits; however, metrological differences were not observed in the higher heating value or the compressibility factor, when calculated by methods A and B of ISO 6974-2.

\subsubsection{Mole fraction of the component between $10 \%$ and $50 \%$ : difference of $\pm 5 \%$}

If the calibration of the chromatograph is considered at standard 1 (sample 2) which contains $11.500 \%$ of ethane; from Table 1, the maximum values of this component to be analyzed must be between $10.925 \%$ and $12.075 \%$. Sample 17 presented $3.000 \%$ of ethane, which is outside the maximum allowable limits; however, metrological differences were not observed in the higher heating value or the compressibility factor, when calculated by methods A and B of ISO 6974-2.

\subsubsection{Mole fraction of the component between $50 \%$ and $100 \%$ : difference of $\pm 3 \%$}

If the calibration of the chromatograph is considered at standard 6 (sample 16) which contains $95.271 \%$ of methane; from Table 1, the maximum values of this component to be analyzed must be between $92.413 \%$ and $98.129 \%$. Sample 5 presented $80.500 \%$ of methane, which is outside the maximum allowable limits; however, metrological differences were not 
observed in the higher heating value or the compressibility factor, when calculated by methods A and B of ISO 6974-2.

In some cases, when standard 7 was utilized (sample 17) to calibrate the chromatograph and make the comparison between the two approaches, the result was unsatisfactory. This could be attributed to the fact that standard 17 is free of pentane, isopentane and hexane, which could upset the standardization of the other components.

When analyzed by standards 2, 3 and 5, sample 2 presented discrepancies between the two methodologies. In this case, the range in Table 1 was possibly not fully extended, in the lower part; i.e. for concentrations of methane below $80.5 \%$, when it became necessary to analyze a sample with values of $71.0 \%$, which extrapolates to a maximum limit of $3 \%$. However, this range of natural gas specification is only required in the North region of Brazil, which lies otoutside the scope of this work, as it does not present a mixture of different currents of natural gas.

When analyzed by standard 4, sample 5 presented discrepancies in values between the two methodologies; however, values in terms of methane concentration showed agreement above and below this point, which indicates that a problem in the analysis may have arisen. Although this discrepancy did not upset the conclusion of the work, it is suggested that this analysis is repeated.

\section{Conclusions}

The results show that it is possible to extend the range of work in Table 1 of ISO 6974-2, without prejudicing either the superior calorific value or the compressibility factor of the natural gas.

Considering the specification of natural gas, Chart 2, whose minimum value for methane is $85.0 \%$ for the Northeast, Central-west, South, and Southeast regions, the results found were satisfactory. That is, with a single gas standard, as for example standard 2 (sample 5 whose methane concentration is $80.5 \%$ ), it is possible to calibrate the chromatograph and analyze currents of natural gas of $82.9 \%$ (3\% of the value of Table 1) to $96.5 \%$ (value allowed by this study). This simplified methodology minimizes the exposure of the operator to this unhealthy activity, in addition to economizing in the cost of acquisition of six further standard mixtures for the calibration with multipoint calibrations. In PETROBRAS, this simplified calibration methodology of chromatographs is already being used in transportation area in custody transfer measurements of natural gas and in the near future it will be implemented in other areas as refining and exploration.

\section{Acknowledgement}

Thanks go to the maintenance technician Wendell Lemos da Silva from the PETROBRAS TRANSPORTE S.A. - TRANSPETRO/DGN/GAS/TGN/RJMG/MNOP Department, who carried out all of the experiments with maximum alacrity.

\section{References}

[1] Analytical Methods Committee. (1995). Uncertainty of measurement - implications of its use in analytical science. Analyst, 120, 2303-2308.

[2] International Organization for Standardization (ISO). (1993). Guide to the Expression of Uncertainty in Measurement, ISO: Geneva, Switzerland.

[3] Bich, W., Cox, M.G., Harris, P.M. (2006). Evolution of the 'Guide to the Expression of Uncertainty in Measurement'. Metrology, 43, S161-S166. 
[4] Cox, M.G., Harris, P.M. (2006). Measurement uncertainty and traceability. Meas. Sci. Technol., 17, 533-540.

[5] EURACHEM/CITAC Guide. (2000). Quantifying Uncertainty in Analytical Measurement, 2nd ed., Ellison, S.L.R., Rosslein, M., Williams, A., Eds., EURACHEM/CITAC: Hungary.

[6] ISO 6974-2:2001. (2006). Natural gas - Determination of composition with defined uncertainty by gas chromatography - Part 2: Measuring-system characteristics and statistics for processing of data. International Organization for Standardization: Geneva, Switzerland.

[7] Wang, D., Wang, S., Zhao, S. (2005). Estimation of the Uncertainty of Fe in Metallic Silicon Determined by Inductively Coupled Plasmas-Atomic Emission Spectroscopy. J. Test. Eval., 33, 3-7.

[8] Miller, J.N., Miller, J.C. (2005). Statistics and chemometrics for analytical chemistry, 5th ed.; Prentice Hall, New York.

[9] Oliveira, E.C. (2011). Critical metrological evaluation of fuels analyses by measurement uncertainty. Metrol. Meas. Syst., 18(2), 235-248.

[10] Oliveira, E.C. (2006). Metrology of natural gas: Evaluation of uncertainty of their physicochemical properties. In Rio Oil and Gas Expo and Conference. (in Brazil)

[11] ISO 6976:1995. (1995). Natural gas - Calculation of calorific values, density, relative density and Wobbe index from composition. International Organization for Standardization: Geneva, Switzerland.

[12] National Agency of Petroleum. Natural Gas and Biofuels.(2008). Resolution No. 16. (in Brazil)

Annex 1. Composition and traceability of the 18 CRMs used in this work.

\begin{tabular}{|c|c|c|c|c|c|c|c|c|c|}
\hline & Curve 1 & Standard 1 & Curve 2 & Curve 3 & Standard 2 & Curve 4 & & Standard 3 & \\
\hline & 1 & 2 & 3 & 4 & 5 & 6 & 7 & 8 & 9 \\
\hline C1 & 68.100 & 71.000 & 72.900 & 78.500 & 80.500 & 84.900 & 88.570 & 88.860 & 89.100 \\
\hline C2 & 11.000 & 11.500 & 8.500 & 7.000 & 11.080 & 5.290 & 3.750 & 6.130 & 7.080 \\
\hline C3 & 2.890 & 2.290 & 4.000 & 3.440 & 1.390 & 1.800 & 0.703 & 1.770 & 2.460 \\
\hline i-C4 & 0.402 & 0.280 & 0.501 & 0.100 & 0.095 & 0.297 & 0.601 & 0.391 & 1.000 \\
\hline C4 & 0.201 & 0.181 & 0.100 & 0.399 & 1.000 & 0.545 & 0.020 & 0.270 & 0.210 \\
\hline i-C5 & 0.201 & 0.180 & 0.100 & 0.299 & 0.250 & 0.020 & 0.050 & 0.110 & 0.040 \\
\hline C5 & 0.200 & 0.180 & 0.150 & 0.298 & 0.220 & 0.245 & 0.050 & 0.070 & 0.020 \\
\hline C6 & 0.202 & 0.180 & 0.100 & 0.249 & 0.170 & 0.050 & 0.020 & 0.100 & 0.050 \\
\hline $\mathbf{N}_{2}$ & 13.960 & 13.000 & 11.240 & 7.970 & 2.230 & 6.760 & 5.880 & 0.742 & 0.000 \\
\hline $\mathrm{CO}_{2}$ & 2.890 & 1.200 & 2.400 & 1.700 & 1.500 & 0.148 & 0.352 & 1.550 & $\overline{0.020}$ \\
\hline TOTAL & 100.046 & 99.991 & 99.991 & 99.955 & 98.435 & 100.055 & 99.996 & 99.993 & 99.979 \\
\hline Certificate & $134 / 10$ & $2826 / 10$ & $130 / 10$ & $2827 / 10$ & 2828/10 & $132 / 10$ & $133 / 10$ & $3488 / 10$ & $2829 / 10$ \\
\hline Cylinder & 5936364 & $2770102 Y$ & 2980543 & 5700929 & $2806800 \mathrm{Y}$ & OI8010 & 153414 & CBO5120 & 6112083 \\
\hline & Curve 5 & Standard 4 & & & Standard 5 & $\begin{array}{l}\text { Curve } 6 \\
\end{array}$ & Standard 6 & $\begin{array}{l}\text { Standard } 7 \\
\end{array}$ & Curve 7 \\
\hline & 10 & 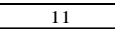 & 12 & 13 & 14 & 15 & 16 & 17 & 18 \\
\hline C1 & 89.820 & 91.000 & 92.100 & 93.480 & 93.600 & 94.000 & 95.271 & 96.500 & 98.000 \\
\hline C2 & 4.338 & 6.350 & 2.200 & 2.000 & 3.210 & 3.230 & 2.807 & 3.000 & 0.881 \\
\hline C3 & 1.490 & 2.200 & 0.050 & 0.750 & 1.150 & 1.080 & 0.348 & 0.400 & 0.071 \\
\hline i-C4 & 0.197 & 0.250 & 0.191 & 0.201 & 0.120 & 0.110 & 0.035 & 0.040 & 0.010 \\
\hline C4 & 0.198 & 0.150 & 0.191 & 0.300 & 0.090 & 0.110 & 0.022 & 0.040 & 0.010 \\
\hline i-C5 & 0.034 & 0.000 & 0.190 & 0.150 & 0.030 & 0.050 & 0.005 & 0.000 & 0.010 \\
\hline C5 & 0.037 & 0.000 & 0.499 & 0.100 & 0.030 & 0.030 & 0.005 & 0.000 & 0.010 \\
\hline C6 & 0.019 & 0.000 & 0.030 & 0.150 & 0.040 & 0.040 & 0.005 & 0.000 & 0.010 \\
\hline $\mathbf{N}_{2}$ & 2.418 & 0.050 & 0.030 & 1.710 & 1.110 & 0.599 & 1.497 & 0.010 & 0.505 \\
\hline $\mathrm{CO}_{2}$ & 1.446 & 0.000 & 4.500 & 1.150 & 0.667 & 0.737 & 0.005 & 0.010 & 0.506 \\
\hline TOTAL & 99.997 & 0.000 & 99.981 & 99.991 & 100.047 & 99.986 & 100.000 & 100.000 & 100.014 \\
\hline Certificate & 40172366 & $2824 / 10$ & $2986 / 10$ & $131 / 10$ & $2797 / 10$ & $2889 / 10$ & 3308/10 & $2890 / 10$ & $2825 / 10$ \\
\hline Cylinder & 14937 & $9750 \mathrm{~B}$ & 5837301 & OI7118 & 275952 & 5700864 & OI7083 & 5700877 & 5936352 \\
\hline
\end{tabular}

Annex 2. Comparative values between method A and method B of ISO 6974-2, in terms of RSCV. The value in each field refers to the real superior calorific value and its associated uncertainty in $\mathrm{kJ} / \mathrm{m}^{3}$.

\begin{tabular}{|c|c|c|c|c|c|c|c|c|}
\hline \multirow[b]{2}{*}{ Sample \%C1 } & \multicolumn{8}{|c|}{ TYPE OF CALIBRATION } \\
\hline & $\begin{array}{c}\text { Analytical cruve } \\
(1,3,4,6,10,15 \\
\text { and } 18)\end{array}$ & $\begin{array}{c}\text { Standard 1 } \\
\text { (sample 2) } \\
71.00 \%\end{array}$ & $\begin{array}{c}\text { Standard 2 } \\
\text { (sample 5) } \\
\mathbf{8 0 . 5 0 \%}\end{array}$ & $\begin{array}{c}\text { Standard 3 } \\
\text { (sample 8) } \\
88.86 \%\end{array}$ & $\begin{array}{c}\text { Standard } 4 \\
\text { (sample 11) } \\
91.00 \%\end{array}$ & $\begin{array}{c}\text { Standard } 5 \\
\text { (sample 14) } \\
93.60 \%\end{array}$ & $\begin{array}{c}\text { Standard 6 } \\
\text { (sample 16) } \\
95.27 \%\end{array}$ & $\begin{array}{c}\text { Standard } 7 \\
\text { (sample 17) } \\
96.50 \%\end{array}$ \\
\hline $2(71.00 \%)$ & $37248 \pm 134$ & & $37536 \pm 107$ & $37762 \pm 113$ & * & $37470 \pm 111$ & $37376 \pm 84$ & 7 \\
\hline $5(80.50 \%)$ & $42111 \pm 143$ & $42093 \pm 112$ & & $42114 \pm 117$ & $\underline{42343 \pm 116}$ & $42035 \pm 115$ & $42117 \pm 108$ & $42664 \pm 124$ \\
\hline $7(88.57 \%)$ & $36814 \pm 143$ & $36787 \pm 98$ & $36898 \pm 98$ & $37014 \pm 99$ & $36519 \pm 100$ & $36877 \pm 130$ & $36844 \pm 94$ & 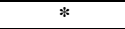 \\
\hline $8(88.86 \%)$ & $39815 \pm 150$ & $39787 \pm 103$ & $39771 \pm 102$ & & $39844 \pm 105$ & $39726 \pm 104$ & $39759 \pm 97$ & $39901 \pm 106$ \\
\hline $9(89.10 \%)$ & $41524 \pm 155$ & $41596 \pm 107$ & $41526 \pm 107$ & $41505 \pm 107$ & $41512 \pm 108$ & $41559 \pm 108$ & $41497 \pm 97$ & $41444 \pm 118$ \\
\hline $11(91.00 \%)$ & $40372 \pm 155$ & $40381 \pm 106$ & $40348 \pm 106$ & $40330 \pm 106$ & & $40296 \pm 106$ & $40306 \pm 97$ & $40287 \pm 108$ \\
\hline \begin{tabular}{|l|}
$12(92.10 \%)$ \\
\end{tabular} & $37157 \pm 156$ & $37153 \pm 199$ & $37156 \pm 99$ & $37156 \pm 99$ & $37166 \pm 98$ & $37171 \pm 99$ & $37270 \pm 132$ & $37181 \pm 105$ \\
\hline $13(93.48 \%)$ & $37916 \pm 154$ & $37878 \pm 99$ & $37893 \pm 99$ & $37929 \pm 100$ & $38080 \pm 100$ & $37899 \pm 100$ & $37917 \pm 107$ & $\underline{38318} \pm 102$ \\
\hline $14(93.60 \%)$ & $38267 \pm 155$ & $38227 \pm 101$ & $38233 \pm 101$ & $38243 \pm 101$ & $38346 \pm 102$ & & $38207 \pm 99$ & $\overline{38472 \pm 103}$ \\
\hline $16(95.27 \%)$ & $37582 \pm 157$ & 3753 & $37560 \pm 102$ & $37581 \pm 102$ & $37713 \pm 102$ & $37541 \pm 102$ & & $37903 \pm 103$ \\
\hline \begin{tabular}{|l|}
$17(96.50 \%)$ \\
\end{tabular} & $38165 \pm 162$ & $38198 \pm 1603$ & $38183 \pm 103$ & $38171 \pm 104]$ & $38176 \pm 103$ & $38161 \pm 103$ & $38160 \pm 101$ & \\
\hline
\end{tabular}

* means that the normalization was $<98 \%$. 